\title{
Effect of Orientation Courses on Self-Regulated Learning Strategies: Goal Setting, Planning, and Execution
}

\author{
Machiko Saeki Yagi*, Mitsue Suzuki*, Shigeki Tsuzuku**, Reiko Murakami*, \\ Hiroshi Nakano** and Katsuaki Suzuki**
}

(Received 14 August 2020 and accepted in revised form 2 March 2021)

\begin{abstract}
Technology and self-regulated learning are necessitated for successful distance learning. In this study, we investigate whether an orientation course that include activities to facilitate self-regulated learning in instructions pertaining to using information communication can help learners succeed in the course. The study population comprises 60 nurses enrolled in an academic medical institution in Japan. Progress through the course and outcomes of performing and modifying learning plans as indicators of self-regulated learning are compared with the results of learners who have completed an analogous course that excludes self-regulated learning activities. The effect of mentor feedback on learners' self-regulation is evaluated. The data obtained from the learning management systems are analyzed via quantitative and qualitative analyses. The results of this study suggest that the experience of rotating the self-regulation cycle in the orientation course increases the learners' metacognition of their thinking process and learning strategies, thereby resulting in the setting of reasonable goals and plan execution.
\end{abstract}

Keywords e-Learning, self-regulated learning, orientation course, reflection

\section{Introduction}

Success in distance learning requires the skilled use of computers and information technology, ability to communicate effectively, and self-regulation of the learning process $^{[1]}$. According to Zimmerman, learners who have mastered self-regulated learning (SRL) are actively involved in three processes: metacognition, motivation, and behavior, and the interplay of these processes results in effective learning outcomes ${ }^{[2]}$. Each of the three processes involves learning strategies to facilitate effective learning. Self-regulation depends on the method by which learning strategies are selected and used efficiently. SRL includes numerous components, and complex interactions are assumed between them; therefore, a model must be developed to explain their synthesis. Zimmerman suggested the triadic effect among people, behavior, and environment-affected selfregulation $^{[2]}$. Meanwhile, self-regulation theorists regard learning as an open-ended process requiring cyclical activities that occurs in three major phases: forethought, performance or volitional control, and self-reflection ${ }^{[3]}$. The forethought phase refers to the influential processes

\footnotetext{
*School of Nursing, Jichi Medical University, Japan

**Research Center for Instructional Systems, Kumamoto University, Japan
}

and beliefs that precede efforts to learn and prepare for learning. Performance or volitional control involves processes that occur during learning efforts and affect concentration and performance. Self-reflection involves processes that occur after learning efforts are expended. Self-reflection affects reactions to the learning experience and forethought in subsequent learning cycles $^{[3]}$. The idea that SRL can be strengthened through intentional practice is widely accepted by researchers. By embedding aspects of SRL in instruction and course content, students' development of SRL competence can be stimulated ${ }^{[4]}$. An online course embedded in instruction activities linked to self-regulatory behavior supported the acquisition of SRL strategies and fostered learner self-regulation ${ }^{[5]}$.

The acquisition of SRL strategies is a time-consuming and difficult task. Learners with the highest success in SRL manage their learning throughout the process and use failure to modify their learning strategies. In problem solving, they read, explore, analyze, plan, implement their plans, as well as evaluate their strategies to identify a solution ${ }^{[6]}$. To become expert self-regulated learners, social and self-directed experiences are necessary. Deci and Ryan ${ }^{[7]}$ proposed an organismic integration theory that presents a stepwise regression from intrinsic motivation to extrinsic motivation and amotivation. The self-regulation process, as considered 
herein, corresponds to Deci and Ryan's motivational state of internalization. If the motivation of learners is extrinsic, then learners require learning support from instructors or mentors to increase their motivation.

Learners can gain social experience through practice with feedback from instructors and mentors. Feedback can initiate and facilitate behavioral changes. As learners become more adept at self-regulation, they will be more equipped to perform their learning autonomously and rely less on instructor/mentor feedback and assistance $^{[3]}$. Thus far, the arrangement of social support and opportunities for independent practice and maximizing learners' self-regulatory development is yet to be elucidated.

Lovett advocated the use of a wrapper, which is a tool for increasing learners' awareness of the metacognitive component in $\mathrm{SRL}^{[8]}$. A wrapper, which contains elements to be applied before, during, and after a course, increases awareness toward SRL strategies (e.g., use of previous learning experiences and implementation of learning plans and interactive learning), thereby improving task performance and learning outcomes. The primary research question for this study is, "Does the implementation of an orientation course aimed at enhancing self-regulation and incorporating a wrapper improve learner performance?" The aim of this study is to investigate the effects of orientation course (OC) improvement on the awareness of learning plans and their revisions in terms of SRL. An OC that precedes the main program and simulates its structure is a goal of this study.

\section{Development of OC for Acquisition of Self-Regulated Learning Strategies}

\subsection{Development of OC}

An OC at a medical training center (Center A) was designed to enable learners to acquire the competencies required to complete a main program comprising 252 hours of study for seven subjects, provided over a 4-month period to gainfully employed nurses ${ }^{[9]}$. The competencies addressed in the OC comprised the technical skills necessitated to use Moodle, a learning management system, and SRL strategies for sustaining distance learning, such as planning, managing, and maintaining learning motivation. The previous OC $(\mathrm{OC}$ v.1) was designed primarily for acquiring technical
Table 1. Contents of OC v.1

\begin{tabular}{|c|c|c|c|}
\hline \multicolumn{4}{|c|}{ OC v.1 } \\
\hline Topics & Contents & Categories & Step \\
\hline 1 & $\begin{array}{l}\text { Check out the Forum activity } \\
\text { for announcement by faculties. }\end{array}$ & Tech & \multirow{9}{*}{ Step2 } \\
\hline 2 & View the File activity. & Tech & \\
\hline 3 & Use the Assignment activity. & Tech & \\
\hline 4 & $\begin{array}{l}\text { Check the submission deadline } \\
\text { on the calendar in the Home } \\
\text { screen. }\end{array}$ & Tech & \\
\hline 5 & $\begin{array}{l}\text { Use the Workshop activity to do } \\
\text { self-evaluation and peer evalua- } \\
\text { tion. }\end{array}$ & Tech & \\
\hline 6 & $\begin{array}{l}\text { Use the Forum activity to dis- } \\
\text { cuss with each other. }\end{array}$ & Tech & \\
\hline 7 & Use the Quiz activity. & Tech & \\
\hline 8 & $\begin{array}{l}\text { Check the checkbox for com- } \\
\text { pletion. }\end{array}$ & Tech & \\
\hline 9 & $\begin{array}{l}\text { Complete the Feedback activity } \\
\text { to answer questions about learn- } \\
\text { ing motivation and self-regulated } \\
\text { learning strategies. }\end{array}$ & Tech/ SRL & \\
\hline 10 & $\begin{array}{l}\text { Make a plan for the main pro- } \\
\text { gram. (via Mahara) }\end{array}$ & Tech/ SRL & Step4 \\
\hline 11 & $\begin{array}{l}\text { Use the Forum activity for tech- } \\
\text { nical questions (Moodle and } \\
\text { Mahara) }\end{array}$ & Tech & - \\
\hline 12 & $\begin{array}{l}\text { Read "How to Study" and set } \\
\text { up the Forum activity subscrip- } \\
\text { tion. }\end{array}$ & Tech & - \\
\hline
\end{tabular}

OC: Orieutation course, SRL: Foster Self-Regulated learning skills, Tech: Train technical skills to use Moodle and Mahara. *Quoted with modifications from [8]

skills to prevent problems in assignment submission for the $\mathrm{OC}$ and main program ${ }^{[9]}$ (Table 1). In addition, OC v.1 included a questionnaire for analyzing learner motivation, tendency in using SRL strategies, and plans for the main program (Topics 9 and 10 in Table 1). The responses reflect the improvement in SRL strategies for the OC.

Considering the extent of subject learning required by the nurses in the main program, it was inferred that more SRL support would benefit nurses in managing their work schedules, obligations, and study requirements. In previous research regarding SRL strategies for 
Table 2. Contents of OC v.2

\begin{tabular}{|c|c|c|c|}
\hline \multicolumn{4}{|c|}{ OC v. 2} \\
\hline Topics & Contents & Categories & Step \\
\hline 1 & $\begin{array}{l}\text { Use the Forum activity for techni- } \\
\text { cal questions (Moodle and Mahara) }\end{array}$ & Tech & - \\
\hline 2 & $\begin{array}{l}\text { Make a plan for Orientation } \\
\text { course. (via Mahara) }\end{array}$ & Tech/ SRL & Step1 \\
\hline 3 & $\begin{array}{l}\text { Check out the Forum activity for } \\
\text { announcement by faculties. }\end{array}$ & Tech & \multirow{9}{*}{ Step2 } \\
\hline 4 & View the File activity. & Tech & \\
\hline 5 & Use the Assignment activity. & Tech & \\
\hline 6 & $\begin{array}{l}\text { Check the submission deadline on } \\
\text { the calendar in the Home screen. }\end{array}$ & Tech & \\
\hline 7 & $\begin{array}{l}\text { Use the Workshop activity to do } \\
\text { self-evaluation and peer evaluation. }\end{array}$ & Tech & \\
\hline 8 & $\begin{array}{l}\text { Use the Forum activity to dis- } \\
\text { cuss with each other. }\end{array}$ & Tech & \\
\hline 9 & Use the Quiz activity. & Tech & \\
\hline 10 & $\begin{array}{l}\text { Check the checkbox for comple- } \\
\text { tion. }\end{array}$ & Tech & \\
\hline 11 & $\begin{array}{l}\text { Complete the Feedback activity } \\
\text { to answer questions about learn- } \\
\text { ing motivation and self-regu- } \\
\text { lated learning strategies. }\end{array}$ & Tech/ SRL & \\
\hline 12 & $\begin{array}{l}\text { Reflect on the learning plan for } \\
\text { the orientation course and estab- } \\
\text { lish a policy for planning future } \\
\text { learning. }\end{array}$ & SRL & Step3 \\
\hline 13 & $\begin{array}{l}\text { Make a plan for the main pro- } \\
\text { gram. (via Mahara) }\end{array}$ & Tech/ SRL & Step4 \\
\hline 14 & $\begin{array}{l}\text { Read "How to Study" and set up } \\
\text { the Forum activity subscription. }\end{array}$ & Tech & - \\
\hline \multicolumn{2}{|c|}{$\begin{array}{l}\text { Read the feedback about learning plan } \\
\text { from mentors. }\end{array}$} & SRL & \\
\hline \multicolumn{2}{|c|}{ Study main program (during 4 months). } & - & Step5 \\
\hline \multirow{2}{*}{15} & $\begin{array}{l}\text { Reflect on the learning plan for } \\
\text { the main program. }\end{array}$ & SRL & Step6 \\
\hline & $\begin{array}{l}\text { Revise learning plans based on } \\
\text { mentors' feedback. }\end{array}$ & SRL & Srep7 \\
\hline
\end{tabular}

OC: Orientation course, SRL: Foster Self-Regulated learning skills, Tech: Train technical skills to use Moodle and Mahara. In OC v.2, "Use the forum activity for technical questions (Moodle and Mahara)" was moved to Topic 1 to enhance learner usability. nurses conducted by the authors of this study, nurses recognized their own shortcomings in planning their learning ${ }^{[10]}$. Additionally, the learning logs from the previous $\mathrm{OC}$ and main programs showed that learning progress decelerated two months after the main program began ${ }^{[11]}$. The nurses' self-acknowledged weaknesses in planning and the observed deceleration in learning progress indicated the necessity for additional support in creating and adjusting a feasible learning plan. The results of these studies ${ }^{[10],[11]}$ strongly suggested that the training in SRL strategies included in OC v.1 was insufficient.

To foster the use of SRL strategies in self-directed learning, three topics were added to OC v.2 (Table 2). A planning activity (Topic 2) was added at the beginning of the course, and combination reflection/main course planning activities (Topics 12 and 15) were implemented near the end. Mentors provided feedback regarding the learning plans between Topics 14 and 15 .

In this study, the mentors provided learning support. Mentors who are knowledgeable and experienced in the content and methodology of the course provided support that contributed substantially to learning continuity and course completion ${ }^{[12]}$. All mentors are nurses with experience in e-learning and are familiar with the main program and its instruction sections. Three mentors participated in this study, one of whom provided feedback primarily and collaborated with the other two in mentoring.

The relationships among the OC, main program, and self-regulation cycle are shown in Fig. 1. In OC v.2, the learners develop a learning plan at the beginning of the course (Step 1). After implementation (Step 2), they write down their reflection of their learning plan as well as their goals and policy plan for the main program in 400 words or fewer (Step 3). The learning plan reflection fulfills the objective of reflective writing ${ }^{[13],[14]}$, i.e., learners observe and analyze their learning process. Prior to writing their reflections, the learners were guided to reflect on the results of the SRL strategies ${ }^{[15]}$. Subsequently, the learners create their learning plans for the main program on Mahara, an e-portfolio system (Step 4).

Mentors analyzed the contents of the reflective writing and learning plans for the main program and provided feedback within 24 hours. As they progress through the main program, learners reflect on their learning plans (Steps 5 and 6) and modify them to 


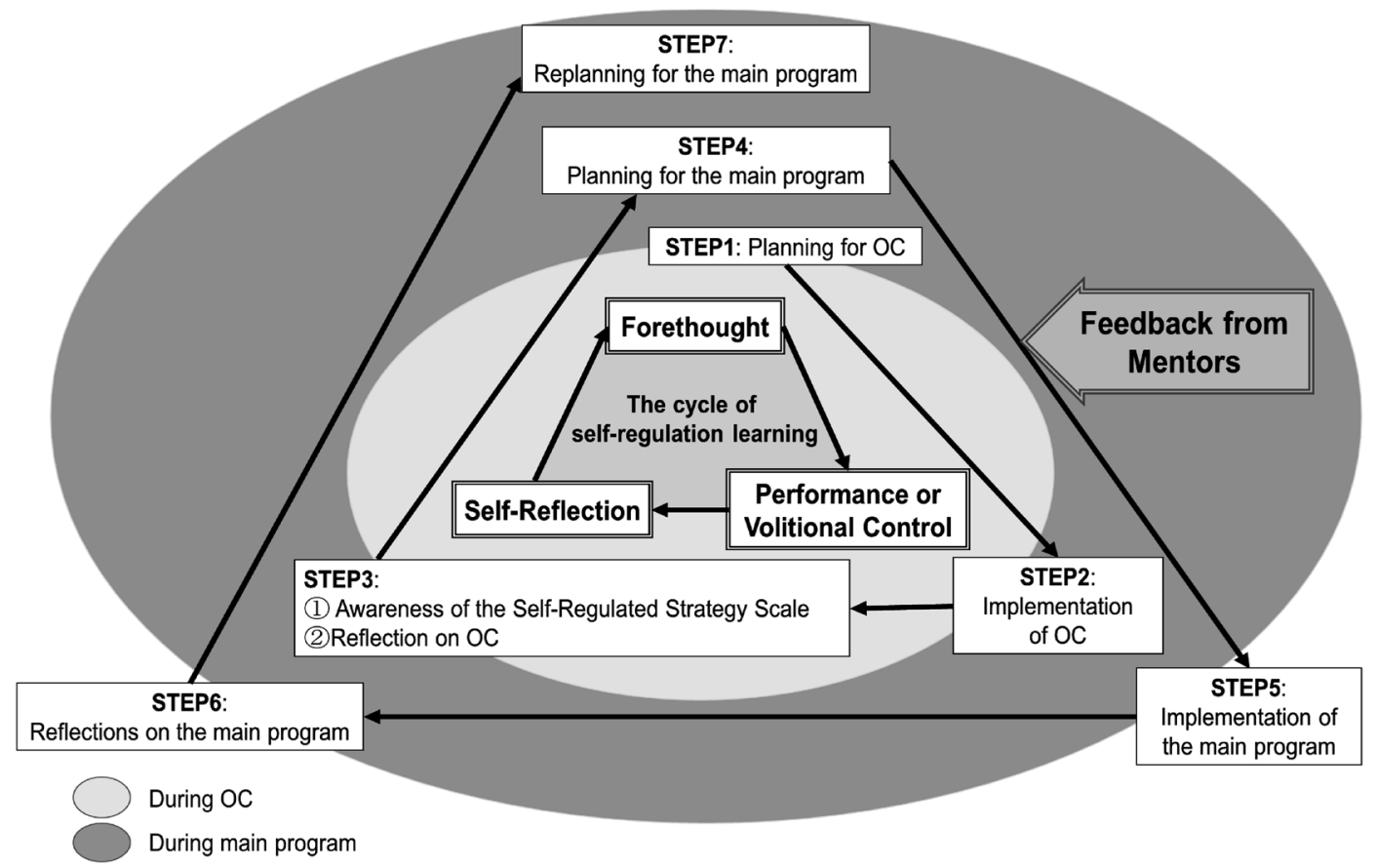

Figure 1. Relationship among OC v.2, main program content, and self-regulation cycles OC: Orientation course.

reflect their work schedules and pace through the program, as reflected by their learning ability for the subject content. By creating their learning plans, learners become familiar with Mahara and managed to schedule 105 learning activities in Moodle synchronously (Figs. 2 and 3).

OC v. 2 was reviewed and revised by a researcher who specialized in information science and technology and SRL.

\subsection{Feedback on Learning Plans and Self- Regulated Learning Strategies}

Formative assessment and feedback are widely used to encourage SRL and augment learner control over task interpretation and learning paths ${ }^{[16],[17]}$. However, many teachers and mentors reported difficulty in providing effective feedback for the advancement of learners. Providing feedback can be burdensome when many learners are involved, whereas inconsistent feedback from teachers and mentors can confuse and frustrate learners. These issues can be mitigated by supplying instructors with specific criteria and content for feedback. In this study, sets of fixed-form sentences for feedback were developed in response to data obtained from learning plans, reflective writing from OCs, and the main programs from the previous four years (Fig. 4).

The learning plan of the main program was classified into three categories to reflect scheduling: reasonable, tight, and slack, based on four years of data pertaining to learner progress as they completed the main program. For each category, a set of context-sensitive, fixed-form sentences were created for feedback (Table 3). Sentences for feedback regarding the SRL strategies were based on five factors identified by Ishikawa and $\mathrm{Kogo}^{[15]}$ : 1. Reflecting on learning methods, 2. Devising learning methods, 3. Asking peers, 4. Developing learning plans, and 5. Rewarding oneself. Mentors were trained to identify and extract descriptions that addressed the learning plan and SRL strategy categories prior to providing learner feedback. 


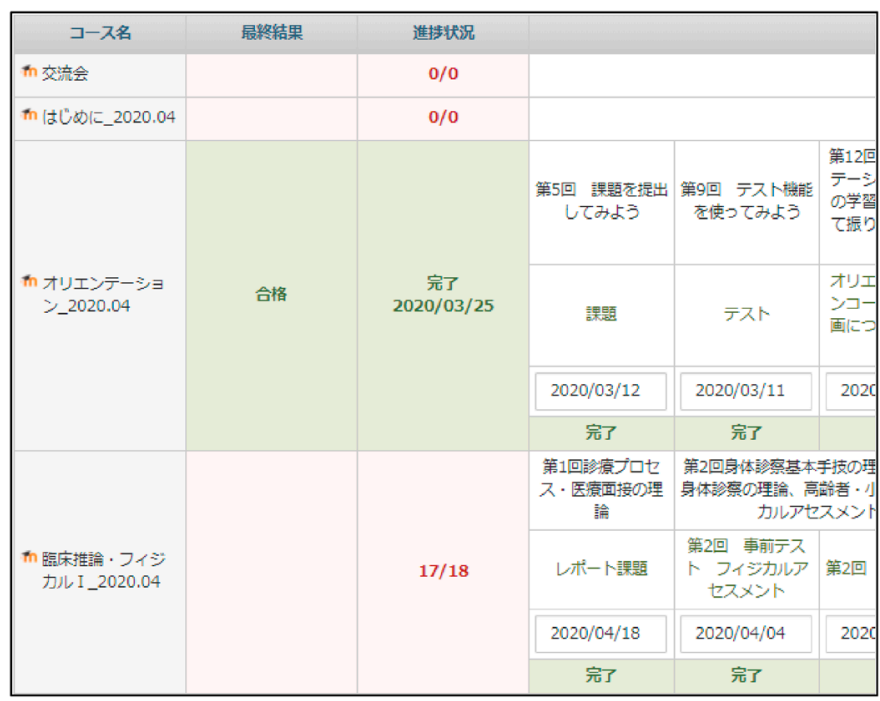

Figure 2. Scheduling of finishing date on Mahara using original plugin (in Japanese)

\subsection{Target Population and Analysis Methods}

The target population for this study was 60 nurses enrolled in medical institutions across Japan. The study was conducted between September 2019 and May of 2020. Thirty learners who used OC v.1 entered Center A in September 2019, whereas the remaining 30 learners used OC v.2 in March 2020. The main program comprised seven subjects with 105 discrete activities investigated over a period of four months. Data pertaining to demographic characteristics were obtained from each learner: age, gender, years of nursing experience, academic background (i.e., highest degree achieved), and special qualifications (e.g., certified nurse or certified nursing specialist).

The study was performed using the feedback and report features of Moodle, an open-source learning platform, and Mahara, the learning management system and e-portfolio system used at Center A. Data were downloaded directly from the Moodle and Mahara servers. The learning plan data of 105 learning activities were extracted from the Mahara learning plan plugin (Figs. 2 and 3). Progress data were extracted from the log function of the Moodle reports. Subsequently, the data from Moodle and Mahara were matched.

The chi-squared test, Fisher's exact test, and independent t-test were performed on the demographic data.
Mann-Whitney $U$ tests were used to compare the number of modifications to the learning plan in OC v.1 and OC v.2. Additionally, a Mann-Whitney $U$ test was used to evaluate the learning plan implementation and progress data in OC v.2. The significance level was set at $5 \%$. IBM SPSS Statistics version 26.0 was used for statistical analysis.

Based on qualitative functional analysis, the learners' reflective writings pertaining to SRL strategies were separated from other content. The writings were first segmented into clauses, and then the semantic content was sorted based on the pre-and post-sentence relationships of the clauses to extract descriptions related to SRL strategies. Descriptions addressing the learning plan were identified and extracted by three researchers. The researchers were trained to identify and extract the descriptions that addressed the learning plan and SRL strategy categories (Table 3). Qualitative functional analysis was performed by one researcher and validated by two other researchers. Independent classifications by the three researchers confirmed few differences.

\subsection{Ethical Considerations}

The aim, purpose, methods, and duration of this study were explained to the prospective participants before they provided consent. The prospective participants 


\begin{tabular}{|c|c|c|c|c|}
\hline SUNDAY & MONDAY & TUESDAY & WEDNESDAY & THURSDAY \\
\hline 29 & 30 & 31 & 1 & 2 \\
\hline 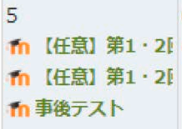 & 6 & 7 & 8 & $\begin{array}{l}9 \\
\text { 而第2回 事骖テス }\end{array}$ \\
\hline 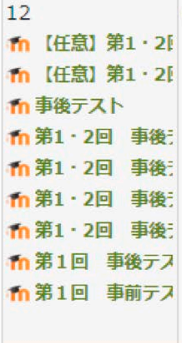 & 13 & 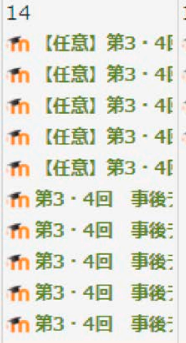 & 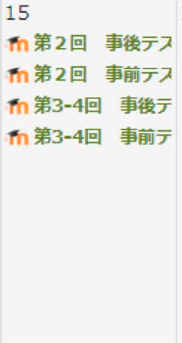 & 16 \\
\hline $\begin{array}{l}19 \\
\text { 向 事後テスト }\end{array}$ & $\begin{array}{l}20 \\
\text { 而第5-6回 事後テ } \\
\text { 而第5-6回 事前テ }\end{array}$ & 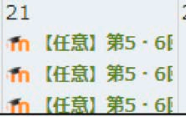 & 22 & 23 \\
\hline
\end{tabular}

Figure 3. Learning plan on Mahara using original plugin (in Japanese)

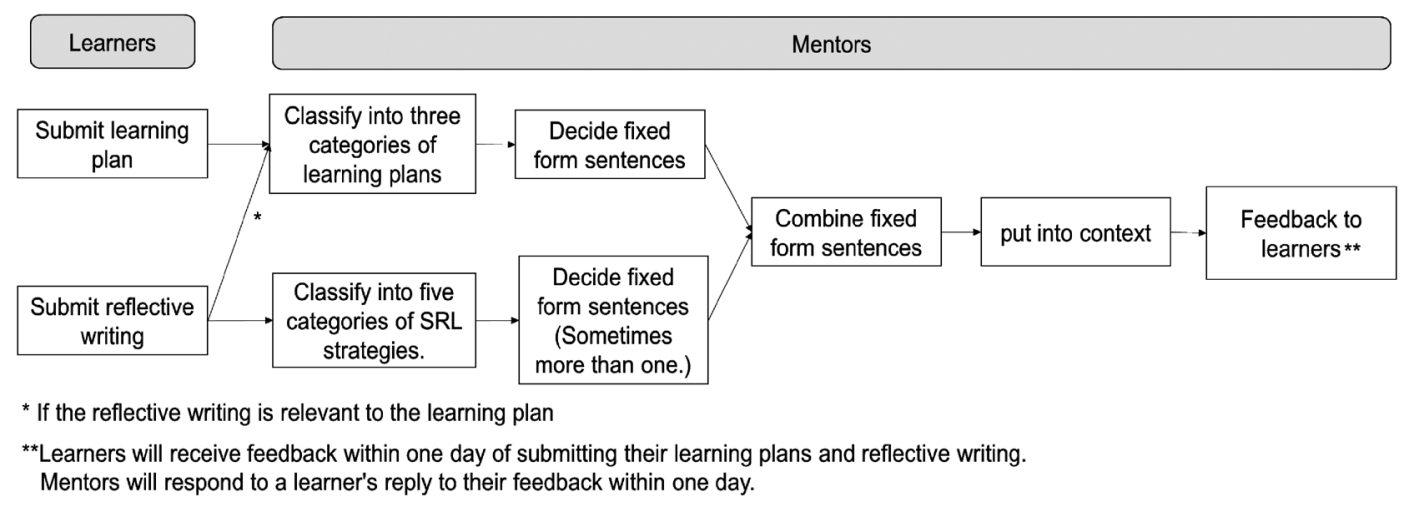

Figure 4. Feedback flow sequence

were advised that their participation was voluntary, their privacy would be protected, and they would not be disadvantaged by declining to participate or withdrawing from the study. Written informed consent was obtained prior to the study. Approval from the Jichi Medical University Clinical Research Ethics Committee (approval number: 16-091) was approved prior to commencing the study.

\section{Results}

OC v.1 and OC v.2 was implemented for one month each. Thirty learners began the OCs and 29 completed each course.

\subsection{Characteristics}

Table 4 shows the demographic data of the learners, 
Table 3. Set of fixed-form sentences for feedback

\begin{tabular}{l|l}
\hline \multicolumn{2}{c}{ Learning plan } \\
\hline Reasonable & $\begin{array}{l}\text { As for the plan to finish the whole process } \\
\text { by*, please proceed at a good pace. Let's } \\
\text { modify the plan as needed. }\end{array}$ \\
\hline Tight & $\begin{array}{l}\text { I have the impression that the plan for* is } \\
\text { tight. } \\
\text { There is plenty of room in the plan for*, } \\
\text { so you may want to revise your study plan } \\
\text { accordingly, taking into account your } \\
\text { actual learning progress. }\end{array}$ \\
\hline Slack & $\begin{array}{l}\text { The plan is to finish the whole thing by*. } \\
\text { Considering the due date of assignments } \\
\text { and review time, I think you may want to } \\
\text { start studying a little earlier. Let's rethink } \\
\text { your study plan as you implement it. }\end{array}$ \\
\hline
\end{tabular}

\begin{tabular}{c|l}
\hline \multicolumn{2}{c}{ Self-regulated learning strategies } \\
\hline $\begin{array}{l}\text { 1. Reflecting on } \\
\text { learning } \\
\text { methods }\end{array}$ & $\begin{array}{l}\text { Review the study plan and progress you } \\
\text { have made, and reflect on whether you } \\
\text { have been able to plan ahead. }\end{array}$ \\
\hline $\begin{array}{l}\text { 2. Devising } \\
\text { learning } \\
\text { methods }\end{array}$ & $\begin{array}{l}\text { Setting aside time and space for learning } \\
\text { is also important in adult distance learn- } \\
\text { ing. With the help of your workplace, you } \\
\text { may be able to find the best learning envi- } \\
\text { ronment. }\end{array}$ \\
\hline $\begin{array}{l}\text { 3. Asking peers } \\
\text { learning } \\
\text { plans }\end{array}$ & $\begin{array}{l}\text { Use the forum to share your questions and } \\
\text { opinions. }\end{array}$ \\
\hline $\begin{array}{l}\text { Check the timing of submission of assign- } \\
\text { ments for main program and work back- } \\
\text { wards in your study plan. It's a good idea } \\
\text { to find out exploratively whether the } \\
\text { learning environment is better at home or } \\
\text { at work, and when the best time is for you } \\
\text { carry out your leaning plan. }\end{array}$ \\
\hline $\begin{array}{l}\text { Coordinate with your family and work- } \\
\text { place so that you can take a break after } \\
\text { your studies. }\end{array}$ \\
\hline
\end{tabular}

*=indicates context-sensitive content

classified into OC v.1 and OC v.2. The gender composition of the learners differed significantly between OC v.1 and OC v.2 $(p=.01)$. No significant difference was observed between OC v.1 and OC v.2 for the other four demographic characteristics.
Table 4. Demographic data of learners

\begin{tabular}{|c|c|c|c|c|c|}
\hline & $\begin{array}{l}\text { OC v.1 }(n \\
\text { number }\end{array}$ & $\begin{array}{c}l=30) \\
(\%)\end{array}$ & $\begin{array}{l}\text { OC v.2 }(n \\
\text { number }\end{array}$ & $\begin{array}{c}n=30) \\
(\%)\end{array}$ & $p$ \\
\hline \multicolumn{6}{|l|}{ Age } \\
\hline mean $\pm S D(y)$ & \multicolumn{2}{|l|}{$40.6 \pm 5.8$} & \multicolumn{2}{|l|}{$40.7 \pm 7.6$} & .94 \\
\hline \multicolumn{6}{|l|}{ Gender } \\
\hline Female & 25 & 83.3 & 16 & 53.3 & \multirow[t]{2}{*}{$.01(F)^{*}$} \\
\hline Male & 5 & 16.7 & 14 & 46.7 & \\
\hline $\begin{array}{l}\text { Work experience } \\
\text { mean } \pm S D(\mathrm{y})\end{array}$ & \multicolumn{4}{|c|}{ Work experience } & .30 \\
\hline \multicolumn{6}{|c|}{$\begin{array}{l}\text { Special Qualifications } \\
\text { (certified nurse or certified nursing specialist) }\end{array}$} \\
\hline yes & 11 & 36.7 & 9 & 30.0 & $.79(F)$ \\
\hline \multicolumn{6}{|l|}{ Academic background } \\
\hline Associate degree & 21 & 70.0 & 15 & 50.0 & .14 \\
\hline Bachelor's degree (College) & 1 & 3.3 & 1 & 3,3 & \\
\hline Bachelor's degree (University) & 5 & 16.7 & 13 & 43.4 & \\
\hline Master's/Doctor's degree & 3 & 10.0 & 1 & 3.3 & \\
\hline
\end{tabular}

(F)Fisher's exact test. OC: Orientation course. $* p<0.05$

\subsection{Analysis of Learning Plan and Reflective Writing}

\subsubsection{Learning Plan Categories in OC v.2}

Twenty-nine learners created learning plans for the main program. Based on the reflective writing and learning plans for the main program in OC v. 2, 14 learners were assigned to the reasonable category, 14 to tight, and one to slack. No significant differences were observed in the demographic characteristics among the learners in the three categories.

\subsubsection{Self-regulated Learning Strategies in OC v. 2}

Twenty-nine learners provided descriptive reflections pertaining to their SRL strategies in OC v.2.

(1) Reflecting on learning methods: 26 reflections. Example: "Implementation was later than planned"; "I tend to proceed earlier than planned."

(2) Devising learning methods: 12 reflections. Example: "I felt that I had to create an environment in which I can concentrate"; "I decided to write down detailed notes and repeat the study."

(3) Asking peers: 11 reflections: Example: "My learning did not improve by relying on the wisdom of friends"; "Help from others was available for identifying the uncertainties, and I am able to ask others for help."

(4) Developing learning plans: 24 reflections. Example: "I will perform the activities as necessi- 
Table 5. Results of self-regulated learning strategies and demographic characteristics in OC v.2

\begin{tabular}{|c|c|c|c|c|c|}
\hline & $\begin{array}{l}\text { 1. Reflecting on } \\
\text { learning methods }\end{array}$ & $\begin{array}{l}\text { 2. Devising learning } \\
\text { methods }\end{array}$ & $\begin{array}{l}\text { 3. Asking } \\
\text { peers }\end{array}$ & $\begin{array}{l}\text { 4. Developing } \\
\text { learning plans }\end{array}$ & $\begin{array}{l}\text { 5. Rewarding } \\
\text { oneself }\end{array}$ \\
\hline & $p$ & $p$ & $p$ & $p$ & $p$ \\
\hline Age & .84 & .86 & .26 & .16 & .69 \\
\hline Gender & $.67(F)$ & $.77(F)$ & $.25(F)$ & $.63(F)$ & $.67(F)$ \\
\hline Work experience & .83 & .33 & .08 & .85 & .89 \\
\hline $\begin{array}{l}\text { Special Qualifications } \\
\text { (certified nurse or certified } \\
\text { nursing specialist) }\end{array}$ & $.53(F)$ & $.69(F)$ & $.74(F)$ & $.15(F)$ & $.64(F)$ \\
\hline Academic background & .84 & .63 & .24 & .85 & .83 \\
\hline
\end{tabular}

$(F)$ Fisher's exact test.

$* p<0.05$

tated"; "I can decide the amount of work, study, and family time"; "I realized I did not have a set time to learn."

(5) Rewarding oneself: Seven reflections. Example: "I would like to enjoy studying and achieve balance between my studies and private life"; "My work and personal times are not clearly defined."

Six learners expressed "anxiety" or "impatience" regarding their future studies.

The chi square test, Fisher's exact test, and independent t-test were performed on the demographic characteristics for each of the SRL strategies. No significant differences were observed (Table 5).

\subsection{Extracting Learning Plans and Performance}

\subsubsection{Revision of Learning Plan}

In the OC v. 1 group, 20 of the 29 learners revised their main program learning plans. In the OC v.2 group, 19 of the 29 learners revised their learning plans. Twelve learners of the OC v.2 group revised their learning plans within two weeks of the mentor's feedback, i.e., seven from the tight category, and five from the reasonable category.

\subsubsection{Implementation of Learning Plan}

The implementation of the learning plan for the first month is shown in Fig. 5. For OC v.2, a significant increase was observed in both "ahead of schedule" and "as planned" ( $p=.002$ and $p=.006$, respectively), whereas a significant reduction was observed in "delayed over the learning plan" $(p=.000)$ as compared with OC v.1. Twelve learners in OC v.2 modified their

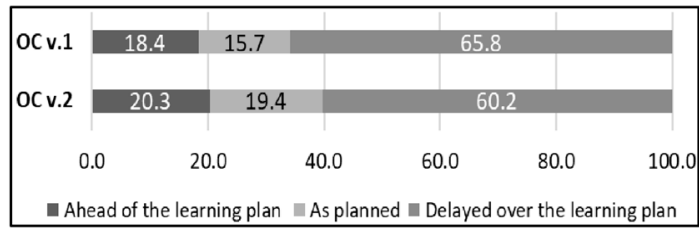

Figure 5. Implementation of study plan in OC v.1 and OC v.2 OC: Orientation course.

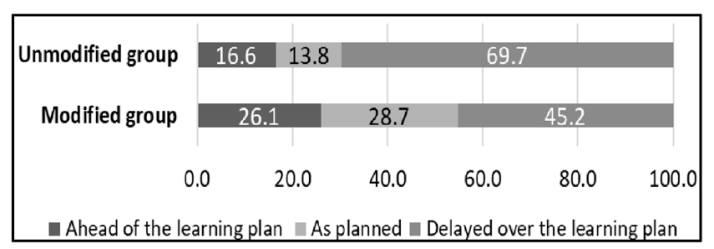

Figure 6. Execution of learning plan with or without learning plan modification OC: Orientation course.

learning plans in response to the mentor's feedback. These 12 learners progressed "as planned" at a significantly higher rate $(p=.036)$ than the 17 learners who did not modify their learning plans (Fig. 6). Additionally, the demographic characteristics remained the same after the learning plan was modified.

\section{Discussion}

\subsection{Effect of Learners' Characteristics}

Few studies have investigated whether differences related to demographic characteristics exist in SRL 
strategies, in particular learning planning. In one study pertaining to goal setting, older adults set lower learning goals and were more likely to restudy activities that were easier rather than more difficult for them ${ }^{[18]}$. Goal setting was included in forethought ${ }^{[3]}$; it was suggested that age affected the planning of learning. In a study pertaining to self-regulation sincerity, it was discovered that gender affected time management outcomes ${ }^{[19]}$. However, in this study, demographic characteristics did not affect the learning plans, SRL strategies, or learning plan modification.

\subsection{Effect of OC Modified for Improving Self-Regulated Learning Strategies}

Deci and Ryan's theory presents analogues in the four stages of self-regulation: the least autonomous analogues were external regulation, introjected regulation, identified regulation, and integrated regulation ${ }^{[7]}$. In the external regulation of learning, characterized by extrinsic motivation with little autonomy, instructors and mentors provided a learning schedule and dictated the speed of learning progress. To achieve autonomous selfregulation (aka integrated regulation), the pace of learning goals was set in accordance with the learner's value system $^{[7]}$. When learners are working adults, a uniform schedule for all learners may not be suitable to their work, personal demands, and schedules. To accommodate this in our study, we instructed the learners to create their own learning plans and schedules, and revisit and revise their plans as required.

In this study, we implemented OC v.2, which was designed to foster a self-regulated cycle of learning planning, implementation, and reflection as a wrapper. The results showed that the students were able to learn more from OC v.2 than from OC v.1, either prior to creating their learning plan or by adopting the learning plan that they had created. In particular, the number of learners who revised their learning plans did not differ between the OC v.1 and OC v. 2 groups; however, the OC v.2 group was able to create and achieve their learning goals more effectively. The content of the learners' reflections revealed that the implementation of OC v.2 rendered many learners conscious and enabled them to verbalize their reflections and learning plans effectively. OC v.1 and OC v.2 differed in terms of planning and reflection, feedback from the mentor, and elaboration of the learning plan based on feedback (Tables 1 and 2).
Herein, data for determining the aspects of independent practice or the manner by which mentors affected learners' planning and execution of learning plans are not provided. However, it can be inferred from this study is that the learning experience of the OC v.2 group in simulating the main program was beneficial. The results suggest an increase in metacognitive skills and improved learning strategies that consequently resulted in appropriate goal setting and the execution of the proposed plan. The OC v.2 of this study suggests that learners benefitted from the wrapper construct of the course and were able to internalize their learning experience.

Second, mentor feedback was identified as the most substantive pedagogical contact point in distance learning; however, providing feedback was difficult from the standpoint of reliability ${ }^{[12]}$. In OC v.2, feedback was aligned with the learning plans and SRL strategies as well as provided via fixed-form sentences. This increased content uniformity reduced the burden on the mentor in providing appropriate comments. From the feedback, it can be inferred that the learners who modified their plans were more successful than those who did not. This result suggests the pedagogical validity of the content of fixed-form sentences in this study.

Additional research pertaining to learners' perception of feedback will contribute to the course design for optimizing SRL. Future studies that include demographic factors and login frequency in relation to SRL strategies and learning plan modification will contribute to the development of appropriate online learning support for continuous professional education. Continued analysis of successful strategies to reduce the rate of delay in implementing the learning plan will aid learners' self-regulation and determination.

\subsection{Limitations}

Because the SRL strategy scale after the implementation of OC v. 2 was not measured in this study, the effect of OC v.2 implementation on the SRL strategy could not be determined directly. Future measurements of the SRL strategy scale after the implementation of OC v.2 will enable us to present valid and reliable results. For future studies, the authors intend to conduct investigations using scales and questionnaires developed based on the situational dependence of SRL strategies as well as a larger study population. 


\section{Acknowledgement}

This study was supported by JSPS KAKENHI (Grant Number 19K10782). I wish to thank Susan Spencer for her assistance in editing this paper.

\section{References}

[1] M. Beaudoin, G. Kurtz, I. Jung, K. Suzuki, and B. L. Grabowski, Online Learner Competencies: Knowledge, Skills, and Attitudes for Successful Learning in Online Settings. Charlotte: IAP, 2013, pp. 9-32.

[2] B. J. Zimmerman, "A social cognitive view of self-regulated academic learning," J. Educ. Psychol., vol. 81, no. 3, pp. 329-339, 1989.

[3] D. H. Schunk and B. J. Zimmerman, Self-Regulated Learning: From Teaching to Self-Reflective Practice. New York: The Guilford Press, 1998, pp. 2-16, 20-38.

[4] G. Van den Boom, F. Paas, J. J. G. van Merriënboer, and T. Van Gog, "Reflection prompts and tutor feedback in a web-based learning environment: Effects on students' self-regulated learning competence," Comput. Hum. Behav, vol. 20, no. 4, pp. 551-567, 2004.

[5] M. Delfino, G. Dettori, and D. Persico, “An online course fostering self-regulation of trainee teachers," Psicothema, vol. 22, no. 2, pp. 299-305, 2010.

[6] L. Nilson, Creating Self-Regulated Learners: Strategies to Strengthen Students' Self-Awareness and Learning Skills. Stylus Publishing Virginia: LLC, 2013, pp. 7-10.

[7] E. L. Deci and R. M. Ryan, Handbook of Self-Determination Research. New York: University of Rochester Press, 2002, pp. 3-27.

[8] M. C. Lovett, "Teaching metacognition," in Presentation to the Educause Learning Initiative Annual Meeting, Jan. 2008.

[9] M. S. Yagi, M. Suzuki, R. Murakami, S. Tsuzuku, H. Nakano, and K. Suzuki, "Preparing for distance learning: Designing an online orientation for nurses," (in Japanese), in Proc. 34th Annual Conf. Educational Technol., Sept. 2018, pp. 435-436.

[10] M. S. Yagi, M. Suzuki, R. Murakami, S. Tsuzuku, H. Nakano, and K. Suzuki, "Analysis of self-regulated learning strategies for nurses in distance learning," (in Japanese), in Proc. Annual Conf. Jpn. Soc. Instruction Syst. in Healthcare, Aug. 2020, p. 37.

[11] M. S. Yagi, M. Suzuki, R. Murakami, S. Tsuzuku, H. Nakano, and K. Suzuki, "Distance learning for nurses: Using learning analytics to build a learning support program,” J. Inf. Syst. Educ., vol. 19, no. 1, pp. 1-8, 2020.
[12] O. Simpson, Supporting Students in Online, Open and Distance Learning. New York: Routledge, 2002, pp. 43-46, 129-133.

[13] J. Landsberger, "The study guides and strategies Website" (www. studygs. net): Ten-year update and current applications," TechTrends, vol. 50, no. 5, p. 5, 2006.

[14] W. Muncil, "Toward objectivity: The history, value and usage of reflective writing," J. Osaka Jogakuin Univ., vol. 3, pp. 111-122, 2006.

[15] N. Ishikawa and C. Kogo, "Causal analysis of self-regulated learning strategies used by adult students in university online courses," (in Japanese), Jpn. J. Educ. Technol., vol. 40, no. 4, pp. 315-324, 2017.

[16] D. J. Nicol and D. Macfarlane-Dick, "Formative assessment and self-regulated learning: A model and seven principles of good feedback practice," Stud. Higher Educ., vol. 31, no. 2, pp. 199-218, 2006.

[17] M. A. Ruiz-Primo and S. M. Brookhart, Using Feedback to Improve Learning. New York: Routledge, 2017, pp. 66-67.

[18] J. Price, C. Hertzog, and J. Dunlosky, "Self-regulated learning in younger and older adults: Does aging affect metacognitive control?," Neuropsychol. Develop. and Cogn. Section B, Aging, Neuropsychology and Cogn., vol. 17, no. 3, pp. 329-359, 2010.

[19] I. S. Lee, "Gender differences in self-regulated on-line learning strategies within Korea's University context," Educ. Technol. Res. Develop., vol. 50, no. 1, pp. 101-111, 2002.

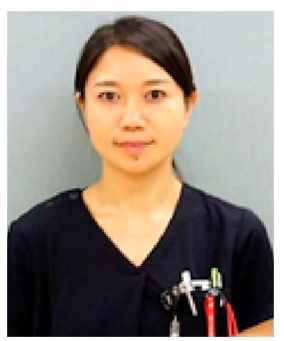

Machiko Saeki Yagi (Ph.D.) is an assistant professor at School of Nursing, Jichi Medical University at Tochigi in Japan. She received her $\mathrm{Ph} . \mathrm{D}$. from Kumamoto University. Her research interests include continuing professional education, technology enhanced learning as distance learning and simulation training, self-regulated learning, and perioperative care.

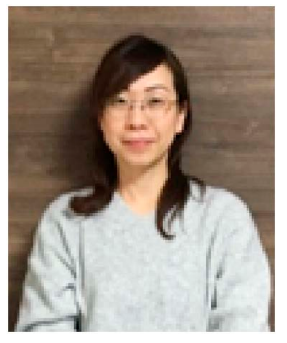

Mitsue Suzuki received the MSPH. from Kanazawa University. She is an assistant professor at the School of Nursing, Jichi Medical University, Tochigi, Japan. Her research interests include education for patients with chronic diseases. 


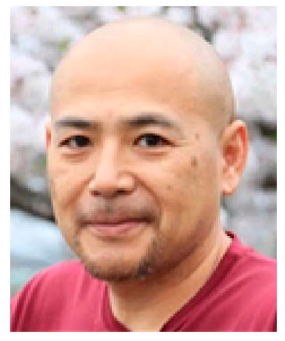

Shigeki Tsuzuku (M.D., Ph.D., $\mathrm{MPH})$ is a professor and chair at the Graduate School of Instructional Systems (GSIS), Kumamoto University, Japan. He received his $\mathrm{Ph} . \mathrm{D}$. from Nagoya University in 1998 and his MPH from the Harvard School of Public Health in 2006. His ongoing research interests are health promotion for non-communicable diseases and the prevention of frailty in aging using instructional design.

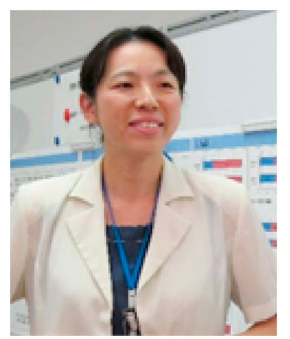

Reiko Murakami (Ph.D.) is a professor at the School of Nursing, Jichi Medical University. She received her Ph.D. from the Graduate School of Health Sciences, Gunma University. Her research interests include effects on the cardiovascular and autonomic nervous systems in healthy adults with different body types while performing movements simulating the washing of the lower limbs for cardiac rehabilitation.

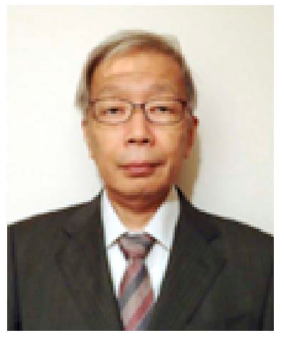

Hiroshi Nakano (Ph.D.) is a professor at the Center for Management of Information Technology, Kumamoto University. He has a Ph.D. from Kyushu University, and his university teaching experiences are physics and information science at Nagoya University, and information education and instructional systems (ICT field) at Kumamoto University. His research focuses on the development of learning support systems, virtual learning environments, e-laboratory systems, and virtual reality for e-learning.

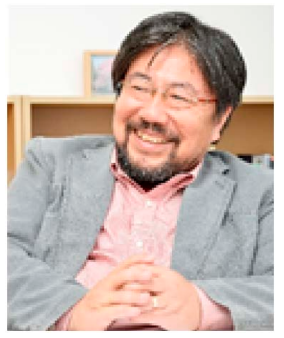

Katsuaki Suzuki (Ph.D.) is a professor at the Research Center for Instructional Systems (RCiS), Kumamoto University, Japan. His ongoing research interests include instructional design theories and models, curriculum design for e-learning professional development, and instructional design and technology for international cooperation. 